I.V. Rybitskyi, A.P. Oliynyk, A.V. Yavorskyi, O.M. Karpash, M.O. Karpash, V.S. Tsykh, M.B. Slobodyan

\title{
Impact Assessment of Non-Technological Fluid Accumulations in the Cavity of an Existing Gas Pipeline on the Energy Efficiency of Its Operation
}

\author{
Ivano-Frankivsk National Technical University of Oil and Gas, Ivano-Frankivsk,Ukraine, rybitsky@gmail.com
}

\begin{abstract}
The given methodology for assessing the efficiency coefficient of a gas pipeline based on the determination of a new informative parameter - the maximum level of non-technological fluid accumulations in its cavity. The proposed methodological approaches make it possible to respond faster regarding the removal of critical volumes of accumulated fluid from the gas pipeline cavity in order to maintain its energy and operational efficiency at the proper level.
\end{abstract}

Keywords: control, fluid accumulations, gas pipeline, efficiency coefficient, level of non-technological fluid accumulations.

Article acted received 29.11.2019; accepted for publication 15.12.2019.

\section{Introduction}

In the context of a continuous increase in the consumption of natural gas and an increase in world prices for it, the requirements to reduce the energy costs of its transmission from the place of production to the final consumer become relevant any time. During operation, various contaminants occur in the cavity of the gas pipelines in the form of solid and liquid fractions, which, accumulating in the lower sections of the pipe, reduce the working section of the gas pipeline, that leads to a decrease in its flow capacity. Studies show that for the entire amount of pollutants, oils and mechanical impurities have up to $2.5 \%$ of the total mass, and the other part for produced, condensed water and gas condensate of various densities [1]. The accumulated fluid in the gas pipeline, as the main barrier to gas transmission, leads to an increase in the pressure drop of natural gas and, as a result, to an increase in energy costs for its transmission. It is also known that the structure of accumulations in a gas pipeline depends on the pumping speed of the gas stream. The volume of accumulations varies in time from the value corresponding to the state of relative dormancy of the deposit (normal volume), and the value corresponding to the burst release of the fluid (critical volume).

The reasons, justifying the occurrence of nontechnological fluids in the system of industrial and main gas pipelines [1, 2, 3] are mentioned below.

1. The presence of the accumulated fluid from the start of the gas pipeline operation as a product removed from the well or as a result of poor-quality cleaning before commissioning. Usually, when a gas pipeline is commissioned, hydraulical testing is performed and water is used as an agent. Neglecting of the requirements for gas pipeline cleaning technology after hydraulical testing leads to the formation of water plugs in the cavity of the gas pipeline and an increase of the hydraulic resistance of the gas pipeline occurs. The analysis of water samples taken from the cavity of the gas pipeline, in this case, detects condensed water with corrosion products of the pipeline wall as the main pollutant.

2. Accidental failures of equipment at gas treatment facilities, their repair or replacement. For this reason, condensate, water, various oil compositions, absorbents of the diethylene glycol type, deposited on the internal sections of the pipeline section after the object, are removed mechanically from the separation and pumping 
equipment.

3. Operation of separation equipment (complex gas treatment equipment) in modes that do not cope with the removal of the natural gas fluid phase. At the beginning of the field development, separation equipment is selected for maximum extraction of fluid phase from natural gas in accordance with the isotherms of natural gas condensation and are calculated on the pressure of maximum condensation in the isothermal process. In the process of the field development the pressure and flow are dropping, the speed in the separator is increasing, internal baffles are wearing, which together lead to the mechanical removal of fluid from the cavity of the separator. In the initial sections of the pipeline, the main component of the accumulation under such conditions will be reservoir water and gas condensate.

4. Changing the composition of the gas condensate system during the field development and corresponding changes in the parameters of maximum condensation. Changing the maximum condensation parameters will cause the removal of the suspended fluid from the separator. The main contaminant of the pipeline is condensed water and light condensate.

5. Creation of an operation temperature regime in the pipeline with favourable conditions for condensation of heavy hydrocarbons and moisture conditions. Reaching of the gas temperature of the limits of dew point temperature during gas transportation through the pipeline section at any of its point will lead to the separation of the fluid phase from the gas stream and the subsequent two-phase flow. Typically, this phenomenon is a characteristic of gas transport in the winter and spring period of operation, when gas preparation is carried out at ambient temperature - air, and the treated gas enters the area at a lower temperature but not yet warmed by the environment (sun rays) - soil. In this case, the pipeline will act as a huge expansion chamber, and the main pollution products will be condensed water and light condensate.

6. Gas pipeline operation at reduced flow. Reduced gas flow in the gas pipeline at relatively constant pressure is characterized by low gas flow velocities. The lower the velocity of the gas stream, the easier the condensed fluid to form accumulation on the lower generating pipeline.

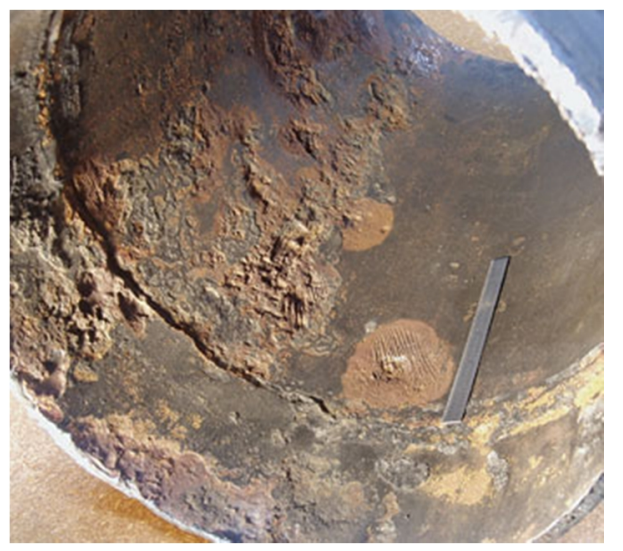

Particular danger arises when part of the fluid condensed in the cavity of the pipeline covers the layer of solid sediments and causes significant corrosion damage to the pipeline wall $[4,5,6]$. In the case of low turbulence of the gas stream, solid sediments may accumulate at the bottom of the horizontal or slightly inclined section of the gas pipeline. An example of the development of strong corrosion that can occur at the bottom section of a pipe under accumulated sediment is shown in Figure 1.

\section{Analysis of modern approaches to liquidation of non-technological fluid accumulations in the gas pipeline cavity}

Gas pipeline cavity purification is a regular and necessary operation. The best results in removing of nontechnological accumulations are achieved with the help of cleaning pigs [7]. However, the cleaning pigs can be used on gas pipelines with a diameter of $219 \mathrm{~mm}$ and which are equipped with cameras for pigs receiving and starting. Such cameras are equipped with not all sections of the main gas pipelines, not to mention the pipelines loops and pipework. The possibility of starting the cleaning pig is significantly influenced by the type of shut-off valves (straight or unequal), the presence of sharp inserts, changes in the diameter of the gas pipeline, gas pipelines crossings through natural and artificial obstacles.

Methods of the gas pipeline transmission in the mode of self-cleaning involve the creation of high-speed mode of the gas pipeline operation due to certain seasonal increased needs of gas supply, as well as in the presence of changes in the mode of the compressors operation at the pressure compressor stations [8]. However, for a single-line gas pipeline, the organization of high-speed gas flow is possible only by increasing the productivity of the section, which eliminates the possibility of using this method for the gas pipeline that supplies gas to consumers as a final transmission, limited to the level of consumption. When cleaning a gas pipeline with the presence of compressor stations in the gaseous pulse

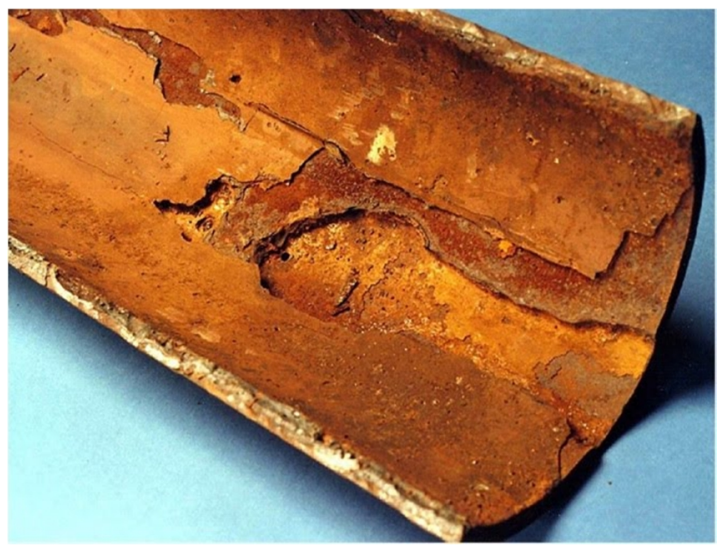

Fig. 1. Corrosion damages at the internal surface of the gas pipeline, caused by the fluid accumulated in its cavity. 

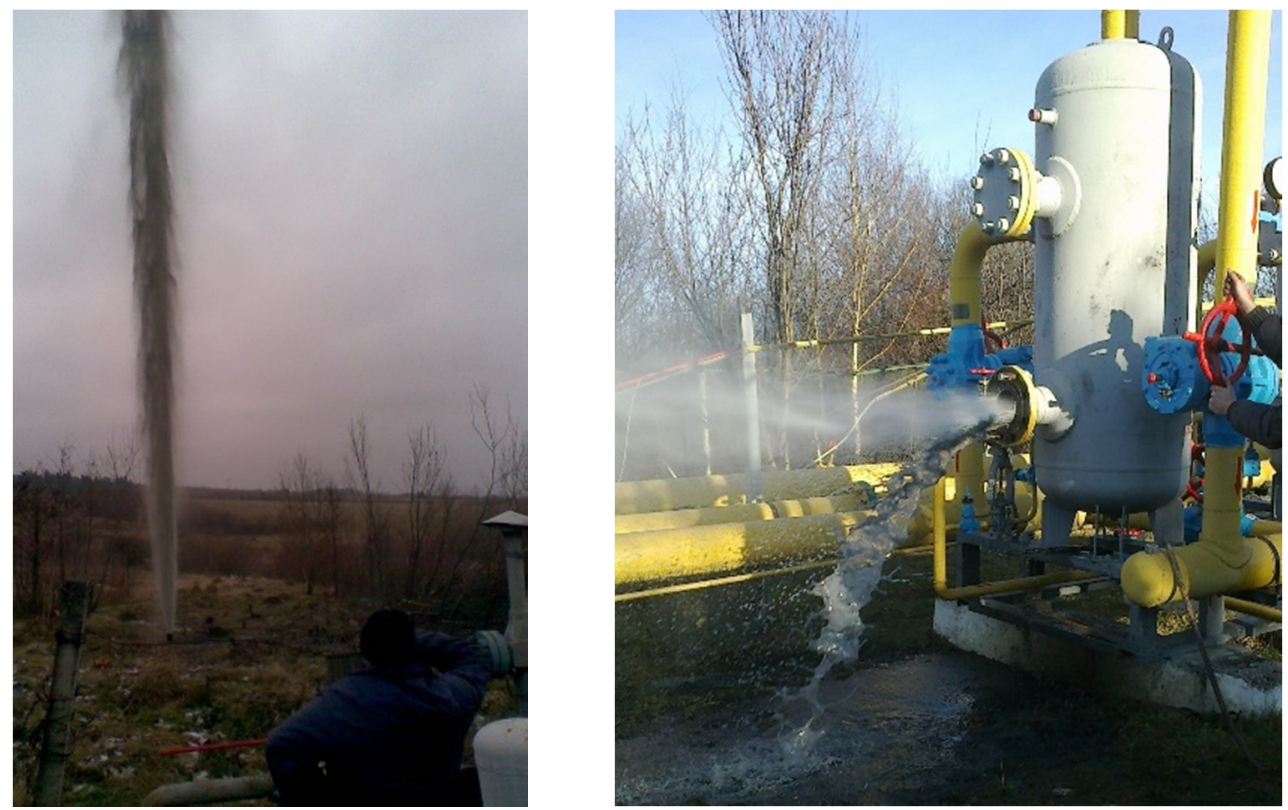

Fig. 2. Accidental gas and fluid release into the atmosphere from the gas pipeline cavity.

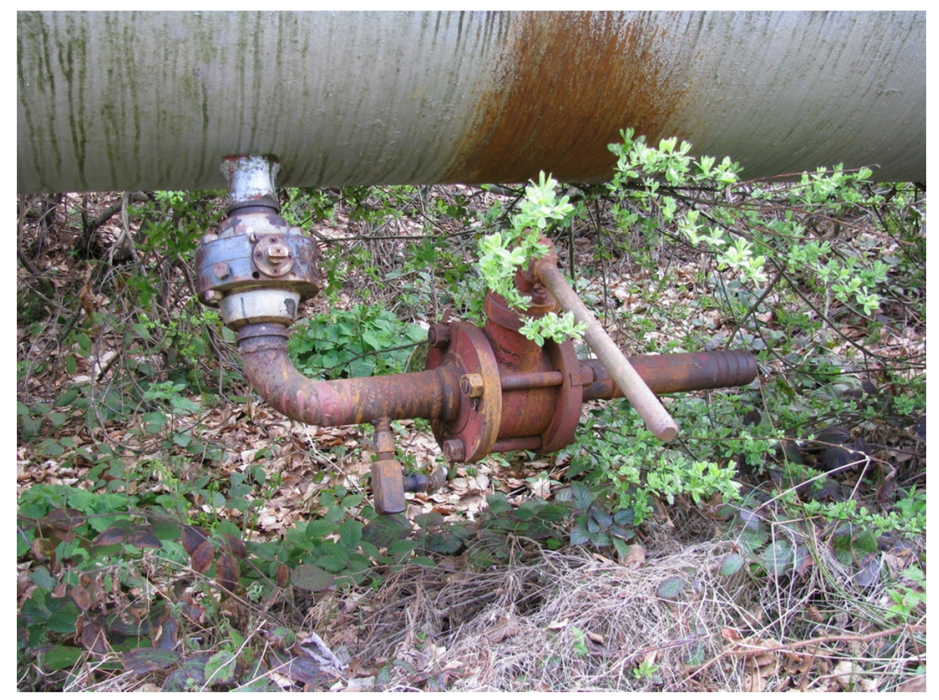

Fig. 3. Insertion of shutoff valves in gas pipeline for fluid drainage.

mode, the working gas flow due to pressure drop is achieved by periodical overlapping the pipeline shut-off valves. The method is also suitable for cleaning singleline gas pipelines, where the short-term mode of pipeline operation can be changed, and the gas consumers' needs are determined at the same time by reducing the accumulation capacity of the pipeline. However, this method, which is widely used in linear sections of gas pipelines, does not take into account the kinematics of the fluid along the pipeline route and the influence of the terrain of the gas pipeline lining, as well as does not allow the determination of the fluid amount carried out from the cavity. Therefore, quite often the use of this method leads to a simple distribution of fluid mass in the congested sections of the pipeline or to salvage accidental emissions of fluid through the equipment with its subsequent failure and pollution (Fig. 2) [9].

An effective method of removing nontechnological fluid from a gas pipeline cavity and an alternative to prior technical solutions is to use stationary devices to drain fluid (drainage) from the gas stream. The use of such devices involves their stationary installation on the pipe of the existing gas pipeline and periodic maintenance associated with the removal of fluid from the receivers of contaminants included in their structure, or purging into the receiving tank. Stationary devices for the fluid removal from the cavity of the gas pipeline can be of two types: contaminants (drips), characterized by the discharge of fluid into the receiver through the connecting pipes on the lower part of the pipeline (Fig. 3) [10]; drainage pipes (traps) that drain the fluid through the upper pipe of the existing gas pipeline.

Placement of drainage devices is determined on the basis of finding the lowest places 
along the pipeline route, as points of the most likely dislocation of non-technological fluid. Such places are found on the basis of the analysis of the longitudinal profile of the route, which is formed by geodetic methods at the stage of engineering surveys for the designed gas pipelines or at the stage of certification for already constructed gas pipelines [11]. The analysis of the route profile shows whether there are places of decline along the gas pipeline in the form of natural beams, river valleys, streams, etc., which are in fact likely sites of fluid accumulation in the gas pipeline cavity, socalled natural fluid traps.

Another critical factor that determines the most likely locations where fluid drainage devices are most appropriate is the critical velocity of fluid removal. With the speed of gas-fluid flow below the critical in certain thermobaric conditions and with a certain pipeline geometry, the transition from the mode of fluid removal to the mode of its accumulation ("Hanging") occurs. On the downstream sections of the pipeline stratified mode is implemented - the fluid flows down the bottom of the pipeline, the gas flow moves above it, with the speed of fluid motion close enough to the speed of gas. Fluid accumulation takes place on the lifting sections, and in case of pipeline intersection with the fluid, a cork flow regime occurs (with generation of low-frequency pulsations of fluid flow). In this case, the mode of fluid accumulation that occurs in the lifting areas leads to a significant decrease in the effective velocity of the fluid phase relative to the gas velocity [12-15]. In the general, the value of the gas stream critical velocity is influenced by the following parameters: the pipeline inner diameter, the fluid accumulation density, he fluid accumulation viscosity, the gas density, the inclination angle of the upstream section of the pipeline to the horizon.

However, the characteristic of a fluid to migrate through a gas pipeline cavity (so-called moving "slugs") does not make it possible to determine the location of fluid accumulation and its level accurately. Given the complexity of gas pipelines relief, especially in mountainous regions, the need to carry out a large volume of earthworks and transportation of tanks to collect fluid from the pipeline, such errors in determining the location of the fluid in the pipeline lead to significant material costs, reduce the productivity of gas transmission system, increase the risk of failures or emergencies.

To solve this problem, the specialists of the

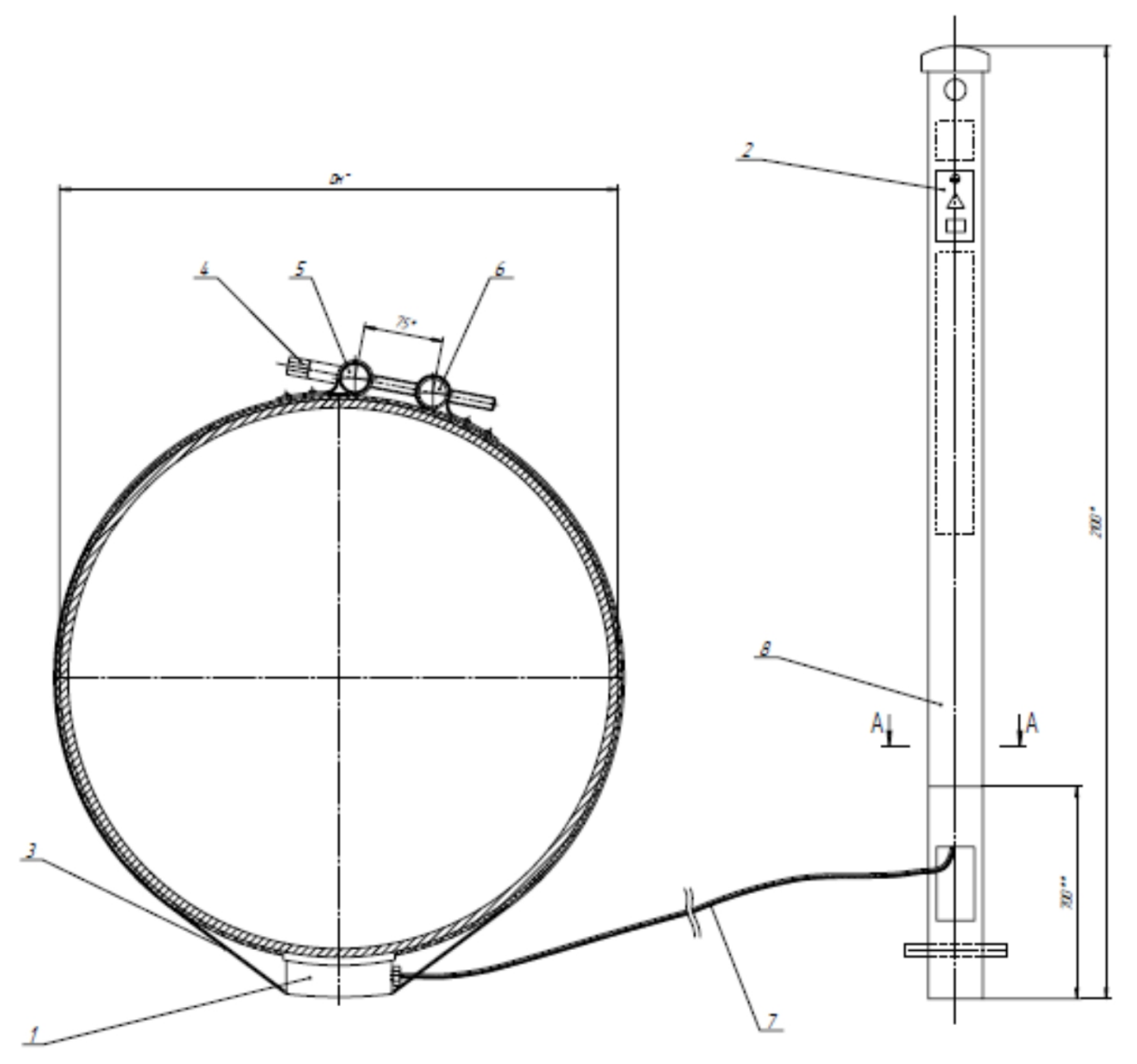

Fig. 4. Monitoring system for fluid accumulation in the gas pipeline cavity: 1 - acoustic unit; 2 - mounting plate; 3 - locking clamp; 4 - coupling bolt; 5 - support sleeve; 6 - tensioning sleeve; 7 - signal cable; 8 - control and measuring post. 


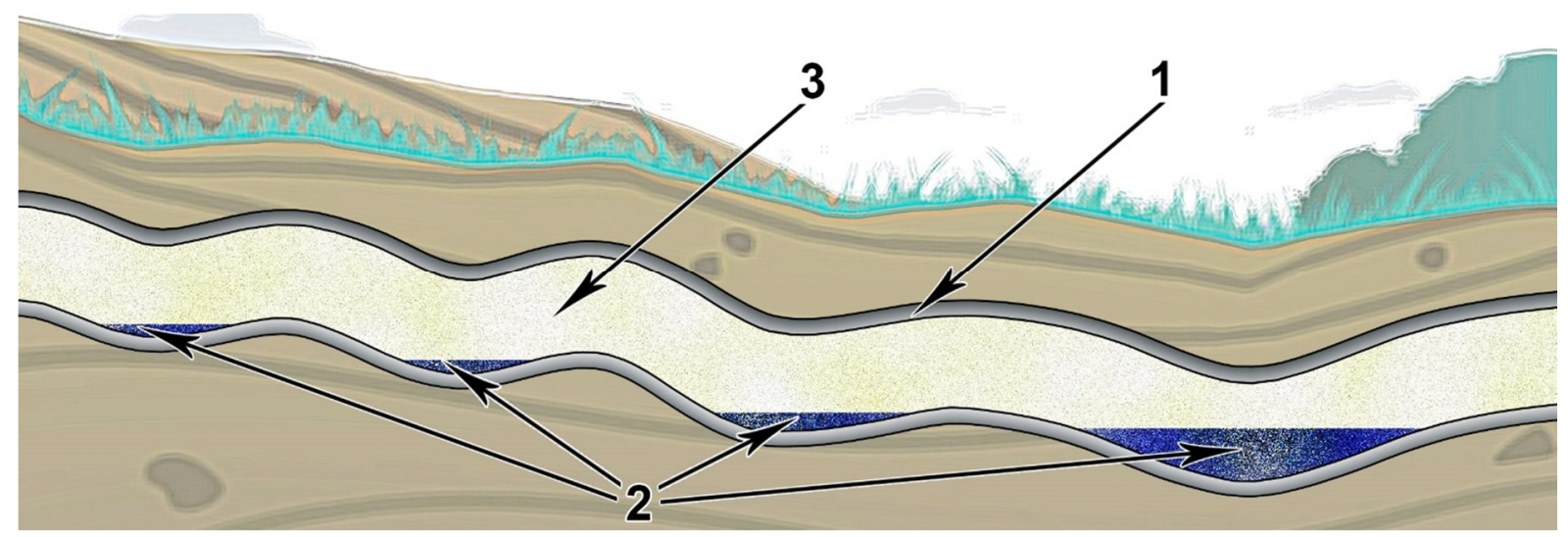

Fig. 5. Pipeline chart, depicting fluid accumulations due to condensation and other causes: 1 - gas pipeline longitudinal profile; 2 - non-technological accumulations (fluid); 3 - natural gas transmissioned.

laboratory for non-destructive testing and technical diagnostics of objects for the oil and gas complex at Ivano-Frankivsk National Technical University of Oil and Gas developed a system for measuring the fluid level in the cavity of the pipeline. The fluid level measuring is carried out in the field without interfering into the pipeline operation [9, 10, 16-19].

The system consists of control posts installed in places where there is a risk of fluid accumulation in the pipeline, and a portable control device. The determination of the fluid level is based on the acoustic echo-pulse method for determining the thickness of the products. The control process consists in the alternate measurement of the fluid level in the pipeline by connecting the control device to each control and measuring post (Fig. 4) [20]. For experimental verification of the proposed solution, a prototype of the control and measuring post was developed, which passed a successful 6year test. The accuracy of measuring the fluid level (at the point of installation of the acoustic ultrasonic sensor), for the developed system, according to experimental studies, was $6.2 \%$.

The implementation of the above-mentioned monitoring system of fluid accumulations from the point of view of the operation of the GTS allows to solve the following problems:

- identification of the most probable places of significant water accumulations occurrence on the basis of the measured fluid level;

- calculation of accumulated fluid volume in the pipeline cavity according to the measurement results.

It is known that the main indicator that determines the operation of a gas pipeline is its efficiency coefficient, which is defined as the ratio of the actual pipeline capacity to the calculated one or as a root of the calculated value of the pipeline hydraulic resistance to the actual one [21, 22]. Accordingly, the study objective highlighted in this article is to obtain a dependence between such information parameter as the maximum level of non-technological accumulations of fluid in the cavity of the gas pipeline (determined by using the control and measuring posts) and the pipeline efficiency coefficient, as the main parameter of energy efficiency of transmission, for on-time decision-making, regarding the removal of critical volumes of accumulated fluid from the gas pipeline cavity to maintain its energy and operational efficiency at the appropriate level.

\section{Research}

When solving the problem of estimating the energy efficiency of a gas pipeline section, caused by the accumulation of non-technological fluid in its cavity on separate sections, the following scheme is considered (Fig. 5):

Suppose $N$ places of fluid accumulation are detected on the section of the pipeline with length $L_{o}$. It is necessary to determine the total volume of fluid in the $L_{o}$ area and the expected capacity loss.

For the pipeline section, the internal and external $R_{k p}^{i}$ radii in each of the sectors (smaller sections) at which the fluid is detected, also, as is stated above, the maximum height of the fluid $H_{i}$, which is determined experimentally, is known. Each of the sectors in which the fluid accumulates can be modelled as follows: the longitudinal section of the pipeline ins considered in the sector, where the fluid accumulation is detected (Fig. 6).

To determine the mid-length of the $A B$ zone, it is necessary to know the radius of curvature of the pipeline axis. Let the coordinates of the points $A, B$ and $O$ be given: $A\left(x_{1} ; y_{1}\right), B\left(x_{2} ; y_{2}\right), C\left(x_{3} ; y_{3}\right)$. Then, the radius of curvature of the pipeline axis can be determined by solving the following system of equations: 


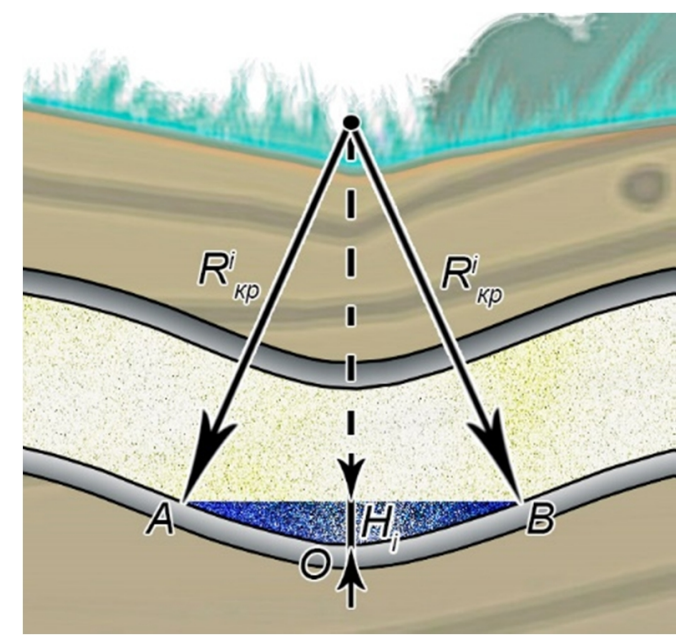

Fig. 6. Longitudinal section of the pipeline sector in which the fluid accumulates.

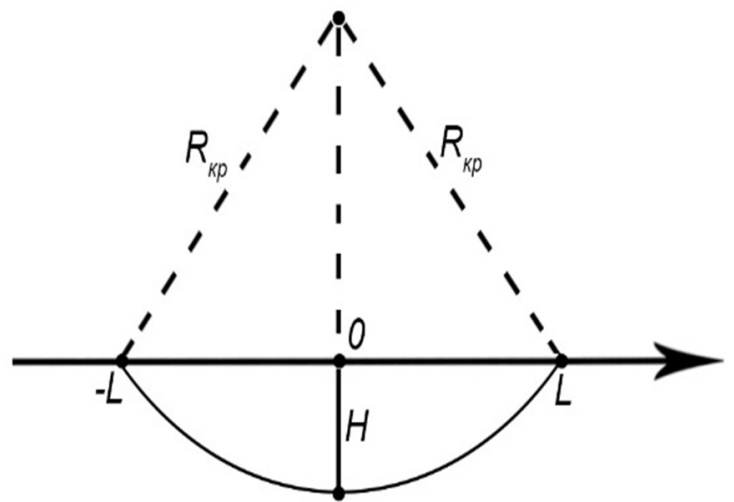

Fig. 7. Schematic longitudinal section of a sectorspecific coordinate system.

$$
\left\{\begin{array}{l}
\left(x_{1}-x_{0}\right)^{2}+\left(y_{1}-y_{0}\right)^{2}=R^{2} \\
\left(x_{1}-x_{0}\right)^{2}+\left(y_{1}-y_{0}\right)^{2}=\left(x_{2}-x_{0}\right)^{2}+\left(y_{2}-y_{0}\right)^{2} \\
\left(x_{1}-x_{0}\right)^{2}+\left(y_{1}-y_{0}\right)^{2}=\left(x_{3}-x_{0}\right)^{2}+\left(y_{3}-y_{0}\right)^{2}
\end{array}\right.
$$

In the system of equations (1), the coordinates of the circle centre of radius $R_{k p}\left(x_{0} ; y_{0}\right)$ and the actual value of $R_{k p}$. are indeterminate. By solving this system of equations by the Kramer's rule [23] it is obtained:

$$
\begin{gathered}
x_{0}=\frac{2\left(x_{2}^{2}-x_{1}^{2}+y_{2}^{2}-y_{1}^{2}\right) \cdot\left(y_{3}-y_{1}\right)-2\left(x_{3}^{2}-x_{1}^{2}+y_{3}^{2}-y_{1}^{2}\right) \cdot\left(y_{2}-y_{1}\right)}{4\left(x_{2}-x_{1}\right) \cdot\left(y_{3}-y_{1}\right)-4\left(x_{3}-x_{1}\right) \cdot\left(y_{2}-y_{1}\right)} \\
y_{0}=\frac{2\left(x_{3}^{2}-x_{1}^{2}+y_{3}^{2}-y_{1}^{2}\right) \cdot\left(x_{2}-x_{1}\right)-2\left(x_{2}^{2}-x_{1}^{2}+y_{2}^{2}-y_{1}^{2}\right) \cdot\left(x_{3}-x_{1}\right)}{4\left(x_{2}-x_{1}\right) \cdot\left(y_{3}-y_{1}\right)-4\left(x_{3}-x_{1}\right) \cdot\left(y_{2}-y_{1}\right)},
\end{gathered}
$$

where:

$$
R_{\kappa p}^{2}=\left(x_{1}-x_{0}\right)^{2}+\left(y_{1}-y_{0}\right)^{2}
$$

Thus, it is assumed that in each sector of fluid accumulation, the value of $R_{k p}$ is given. In this case, a sector-related coordinate system is showed, in which the longitudinal section is schematized as follows (Fig. 7):

Value $L$ is determined by the formula:

$$
L=\sqrt{R_{\kappa p}{ }^{2}-\left(R_{\kappa p}-H\right)^{2}}=\sqrt{2 R_{\kappa p} H-H^{2}} \text {. }
$$

When considering the cross-section of a gas pipeline section on which non-technological accumulations are detected, the geometric parameter that needs to be known is the radius of the pipeline $\mathrm{R}$ (Fig. 8):

In this case, in each cross section its area is expressed by the formula:
$S(y)=\frac{1}{2} \arcsin \frac{R-y}{R} \cdot R^{2}-\frac{1}{2}(R-y) \sqrt{R^{2}-(R-y)^{2}}$

where:

$$
y=-R_{\kappa p}+H+\sqrt{R_{\kappa p}^{2}-x^{2}}
$$

This means that the fluid completely fills some of the rotation ellipsoid in the form of (Fig. 9):

$$
\frac{x^{2}}{R^{2}}+\frac{y^{2}}{R^{2}}+\frac{z^{2}}{L^{2}}=1
$$

where $R$ - pipeline radii, and $L-$ is calculated by (4).

Thus, by replacing the value $y$ in expression (5) by expression (6), its area in the cross-section filled with the fluid, is obtained:

$$
\begin{aligned}
& S(x)=\frac{1}{2} \arcsin \left[\frac{R+R_{\kappa p}-H-\sqrt{R_{\kappa p}{ }^{2}-x^{2}}}{R}\right] \cdot R^{2}- \\
& -\frac{1}{2}\left(R+R_{\kappa p}-H-\sqrt{{R_{k p}}^{2}-x^{2}}\right) \sqrt{R^{2}-\left(R+R_{\kappa p}-H-\sqrt{R_{k p}{ }^{2}-x^{2}}\right)^{2}}
\end{aligned}
$$


So, the volume of the fluid-filled sector is calculated by the formula:

$$
\begin{aligned}
V & =\int_{-L}^{l} S(x) d x=\int_{-L}^{L} \frac{1}{2} \arcsin \left[\frac{R+R_{\kappa p}-H-\sqrt{R_{\kappa p}{ }^{2}-x^{2}}}{R}\right] \cdot R^{2} d x- \\
& -\int_{-L}^{L} \frac{1}{2}\left(R+R_{\kappa p}-H-\sqrt{R_{\kappa p}{ }^{2}-x^{2}}\right) \cdot \sqrt{R^{2}-\left(R+R_{\kappa p}-H-\sqrt{R_{\kappa p}{ }^{2}-x^{2}}\right)^{2}} d x
\end{aligned}
$$

Formula (9) allows to obtain the loss of capacity volume of the pipeline due to the accumulation of fluid.

Then $V_{0}$ is the initial volume of the pipeline and $L_{0}$ its length. Suppose that $N$ sections of fluid accumulation were detected in the study area, in each of which the maximum height of the fluid layer is $H_{i}$. Thus, the total volume loss due to fluid accumulation is:

$$
V_{\text {вm }}=\sum_{i=1_{i}}^{N} V_{i},
$$

where $V_{i}$ - Volume if fluid in $i$-sector, calculated according to (9):

$$
V_{i}=\int_{-L_{i}}^{L_{i}} S_{i}(x) d x,
$$

where: $\pm L_{i}$ - longitudinal size $i$-sector; $S_{i}(x)$ calculated by (9), provided that $R_{k p}^{i}$ - the radius of $i$-sector curvature and $H_{i}$ - fluid depth in $i$-sector are specified.

Thus, the total volume loss in the pipeline section of length $L_{O}$ is $V_{B T}$ and is calculated by (10).

To evaluate the loss of the pipeline section efficiency, the following scheme is suggested: considering that the length of the pipeline $L_{0}$ remains constant, and, in the absence of fluid in the pipe, its cross-sectional area is $\pi R^{2}$ - where $\mathrm{R}$ is the constant

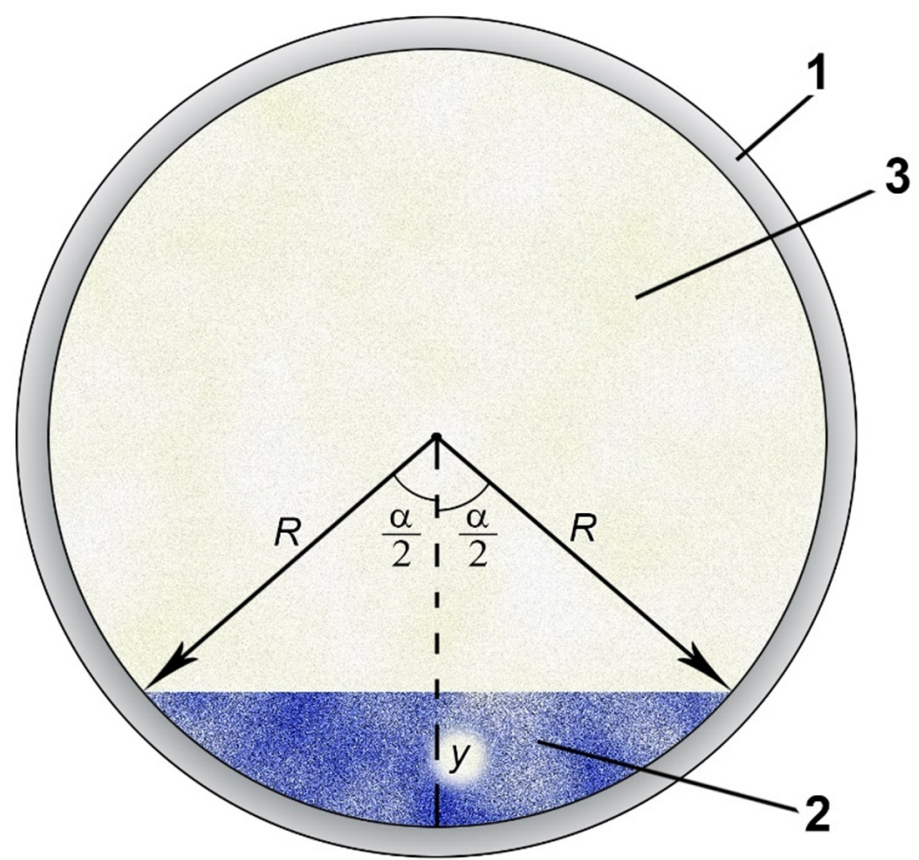

Fig. 8. Cross section of a pipeline sector in which fluid accumulates due to the condensation and other causes: 1- cross-section profile of the pipeline; 2 - non-technological accumulations (fluid); 3 - natural gas transmissioned.

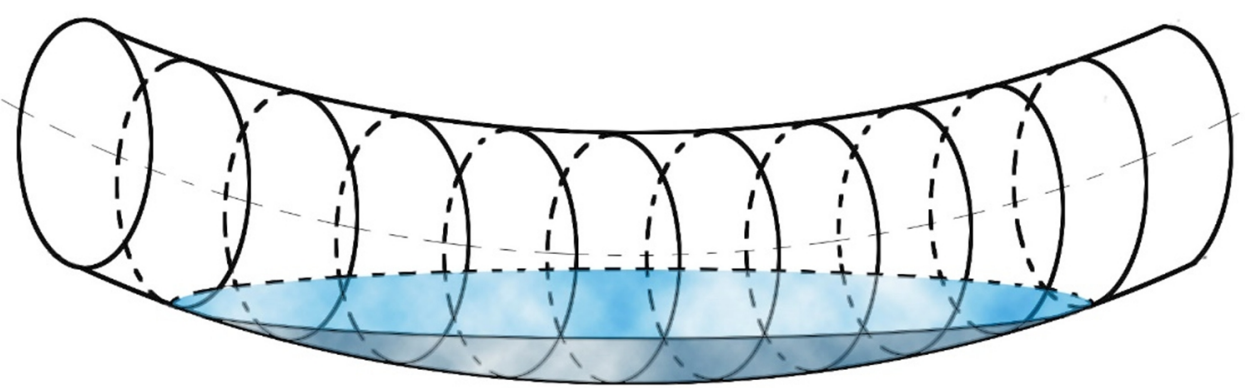

Fig. 9. Schematic representation of the pipeline cavity filling with the fluid. 
radius of the pipeline, the volume of the study section can be calculated formula:

$$
V_{0}=L_{0} \cdot \pi R^{2}
$$

After filling a part of the pipeline with a fluid, its volume, suitable for transmission of the product, decreases and is:

$$
V_{H}=V_{0}-V_{B T},
$$

where $V_{0}$ is calculated according to the expression (12), and $V_{B T}$-according to the expression (10).

Introducing the concept of effective cross-sectional area $S_{H}$, it is calculated as follows:

$$
S_{H}=\frac{V_{0}-V_{B T}}{L_{0}} \neq \pi R^{2}
$$

where $S_{H}<\pi R^{2}$.

According to this estimation, to ensure a constant value of the product flow (providing the required volume of natural gas pumping) $Q_{0}$ through the pipeline with fluid, it is necessary to spend additional energy, for example, to increase the flow rate of the natural gas being transported by an amount that can be defined by the formula:

$$
Q_{0}=V_{0} \cdot S_{0}=V_{0} \cdot \pi R^{2}=V_{1} S_{H},
$$

where:

$$
V_{1}=\frac{S_{0} \cdot V_{0}}{S_{H}},
$$

and it is evident that $V_{1}>V_{0}$.

This scheme is approximate, the increase in the speed of the product pumping is due to the increase in pressure difference between the two compressor stations, which are the start and end points of the study area.

Another approach could be as follows: if the initial radius of the pipeline is $R_{0}$ and the product flow velocity is, in the simplest case, described by the Poiseuille flow [24] according to the following formula:

$$
V=\frac{i}{4 \mu}\left(R_{0}^{2}-r^{2}\right)
$$

In the pipeline with areas where the fluid accumulates, the decrease $R_{0}$ changes, then in $\mathrm{s}$ for engineering calculations it is possible to assume that:

$$
S_{H}=\frac{V_{0}-V_{B T}}{L_{0}} \approx \pi R_{1}^{2},
$$

with a view that the cross-sectional shape is slightly different from the circle shape:

$$
R_{1} \approx \sqrt{\frac{S_{H}}{\pi}}<R_{0},
$$

then:

$$
V_{1}=\frac{i}{4 \mu}\left(R_{1}^{2}-r^{2}\right)<V_{0}
$$

Therefore, the magnitude of the pressure gradient required to ensure the pumping level Q0 can be approximately determined from the formula:

$$
\begin{gathered}
Q_{0}=\frac{i R_{0}^{4} \pi}{8 \mu}=\frac{i_{1} R_{1}^{4} \pi}{8 \mu}, \\
i_{1}=i \cdot \frac{R_{0}^{4}}{R_{1}^{4}},
\end{gathered}
$$

where $i$ - the pressure difference at the ends of the pipeline, $\mu-$ dynamic viscosity of natural gas, where $i_{l}>$ $i$, because $\frac{R_{0}^{4}}{R_{1}^{4}}>1$.

From the technical parameters of the compressor station it is known how much energy is needed to increase the pressure in the pipeline, which would guarantee the preservation of the constant $Q_{0}$.

\section{III.Discussions and Conclusions}

Various accumulations and pollutants in the cavity of the existing main gas pipelines reduce the working cross section of the gas pipeline sections, which in turn leads to a decrease in their capacity, an increase in pressure drop and an increase in energy losses during natural gas transmissions by the main gas pipelines. In addition, the fluid condensed in the cavity of the pipeline, which covers the layer of solid sediments, causes significant corrosion damage to the pipeline wall and can cause accidents to the pipeline section

These days, there are a number of approaches to eliminate the accumulation of non-technological sediments and fluids in the gas pipeline cavity, but the ability of a fluid to migrate through a gas pipeline cavity does not make it possible to determine the location of fluid accumulation and its level accurately. A stationary system for measuring the level of fluid in a gas pipeline cavity and the method of determining locations of potential accumulations of non-technological sediments and fluids in a gas pipeline cavity reduce significantly the need for a large volume of earthworks and transmission of collection tanks for collecting the fluid from the pipeline.

The obtained dependence between the maximum level of non-technological accumulations of fluid in the cavity of the gas pipeline and the coefficient of the gas pipeline efficiency, as the main parameter of energy efficiency for natural gas transmission, allows to make on-time decisions on the need to extract critical volumes of accumulated fluid from the cavity of the gas pipeline and maintain energy and operational capacity of the pipeline. It is shown that even a relatively small reduction in the inner radius of the pipeline caused by the presence of non-technological accumulations can lead to a significant increase in energy costs to provide the required volume of natural gas pumping. 
Rybitskyi I.V. - Ph.D., Associate Professor, Associate Professor, Department of Energy Management and Technical Diagnostics;

Oliynyk A.P. - Professor, Doctor of Technical Sciences, Head of the Department of Applied Mathematics;

Yavorskyi A.V. - Ph.D., Associate Professor, Associate Professor, Department of Energy Management and Technical Diagnostics;
Karpash O.M. - Professor, Doctor of Science (Engineering), Professor, Department of Energy Management and Technical Diagnostics;

Karpash M.O. - Professor, Doctor of Science (Engineering), Professor, Department of Energy Management and Technical Diagnostics;

Tsykh V.S. - Ph.D., Associate Professor, Department of Energy Management and Technical Diagnostics;

Slobodyan M.B. - PhD student in the Department of Energy Management and Technical Diagnostics.

[1] A.V. Yavorskii, R.Yu. Banahevuch, I.V. Rybitskyi, M.O. Karpash, O.M. Karpash, 4-th International Science and Technical Conference Oil and Gas Energetics 2015 (Goliney O.M., Ivano-Frankivsk, 2015). P. 258 (doi: 10.31471/1993-9868).

[2] M.E. Usoltsev, A.A. Korshak, Mountain Information and Analytical Bulletin (scientific and technical journal) (12), 36 (2011) (doi: 10.25018/0236-1493).

[3] E.S. Potapenko, Y.M. Koklyn, Pipeline transport: theory and practice (2), 19 (2015) (doi: 10.15217/issn1998984-9.2015.30.13).

[4] N. Sridhar, D.S. Dunn, A.M. Anderko, M.M. Lencka, H.U. Schutt, NACE/Corrosion - 2001 57(3), 221 (2001) (doi: 10.5006/1.3290347).

[5] X.G. Zhang, Uhlig's Corrosion Handbook 3nd edition. Electrochemical Society Series (John Wiley \& Sons Ltd., Singapore, 2011) (doi: 10.1002/9780470872864.ch62).

[6] R. Nybrorg, A. Dugstad, NACE/Corrosion - 2007, 10 (2007) (doi: 10.5006/1.3290347).

[7] A.A. Korshak, M.E. Usoltsev, V.V. Pshenyn, Network publication "Oil and Gas Business" 5, 290 (2015) (doi: 10.17122/ogbus-2015-5-290-335).

[8] E.S. Potapenko, Oil and gas technology - 2012 (4), 61 (2012).

[9] R.Iu. Banakhevych, A.V. Yavorskyi, M.O. Karpash, Ya.V. Rozhko, S.V. Velykyi, Oil and Gas Energetics 1(21), 55 (2014) (doi: 10.31471/1993-9868).

[10] O.M. Karpash, R.Iu. Banakhevych, M.O. Karpash, A.V. Yavorskyi, I.V. Rybytskyi, lectronic scientific journal "Oil and Gas Business" 5, 244 (2013) (doi: 10.17122/ogbus-2013-1-77-94).

[11] B. Barrau, Oil \& Gas Journal 98(8), 58 (2000) (ISSN: 0030-1388).

[12] A.N. Krasnov, Network publication "Oil and Gas Business" 16(4), 118 (2010) (doi: 10.17122/ogbus-2015-5290-335).

[13] Ge. Jianzhi, PSIG Annual Meeting. Pipeline Simulation Interest Group 12, 207 (2009).

[14] E.C. Potapenko, Gas industry, 9(679), 44 (2012).

[15] E.S. Potapenko, I.M. Koklin, I.F. Malenkina, Gas industry 4(689), 47 (2013).

[16] O.M. Karpash, I.V. Rybitskiy, A.V. Yavorskiy, Gas industry 12, 13 (2011).

[17] I.V. Ryibitskiy, A.V. Yavorskiy, R.Yu. Banahevich, Scientific Proceedings 1(121), 93 (2011).

[18] R.Iu. Banakhevych, A.V. Yavorskyi, M.O. Karpash, Quality control methods and instruments 1(32), 107 (2014) (doi: 10.31471/1993-9981).

[19] O.M. Karpash, I.V. Rybitskyi, M.O. Karpash, R.Iu. Banakhevych, Patent №UA106840C2 Ukraine, MPK (2014.01) G01F 23/00. - № a 201309982.

[20] Fluid accumulation monitoring system. Specifications. TU U 26.5-02070855-001:2016.

[21] Yu.A. Frolov, V.F. Novoselov, Cleaning of the cavity of existing main pipelines (Ufa Oil and Gas Institute Pablisher, Ufa, 1989).

[22] Ie.I.Iakovliev, O.S.Kazak, V.B.Mykhalkiv, Modes of gas transportation systems (Svit, Lviv, 1992).

[23] G. Korn, T. Korn, Math reference book for scientists and engineers (Nauka, Moscow, 1984.

[24] P.I. Sedov, Continuum mechanics (Nauka, Moscow, 1984). 
I.V. Rybitskyi, A.P. Oliynyk, A.V. Yavorskyi, O.M. Karpash, M.O. Karpash, V.S. Tsykh, M.B. Slobodyan

I.В. Рибіцький, А.П. Олійник, А.В. Яворський, О.М. Карпаш, М.О. Карпаш, В.С. Цих, М.Б Слободян

\section{Оцінка впливу нетехнологічних рідинних скупчень в порожнині діючого газопроводу на енергоефективність його роботи}

Івано-Франківський наџіональний технічний університет нафти і газу, м. Івано-Франківськ, Украӥна, rybitsky@gmail.com

Описана методика оцінювання коефіцієнту ефективності роботи газопроводу на базі визначення нового інформативного параметра - максимального рівня нетехнологічних скупчень рідини в його порожнині. Запропоновані в статті методичні підходи дозволяють оперативно приймати рішення, щодо вилучення критичних обсягів накопиченої рідини 3 порожнини газопроводу для підтримання його енергетичної та експлуатаційної ефективності на належному рівні.

Ключові слова: контроль, рідинні скупчення, газопровід, коефіцієнт ефективності, рівень нетехнологічних скупчень рідини. 